\title{
Development of Vulnerability Module for Inland Flood CAT Models in Central European Countries
}

\author{
Raulina Wojtkiewicz ${ }^{1, a}$, Yang Gao \\ ${ }^{1}$ AIR Worldwide, Two Avenue de Lafayette, Boston, MA-02111, USA
}

\begin{abstract}
Flooding is a ubiquitous and frequent hazard in Central Europe in both low-lying river valleys and off the floodplains. Recent record-breaking inland floods, such as the Central European floods of 2013, are a stark reminder of the loss potential they hold. To estimate losses from inland flood events a comprehensive catastrophe (CAT) model was developed. The model framework incorporates an event-based fully-probabilistic hazard model and a vulnerability model. The vulnerability model estimates losses from on- and off- floodplain hazards by modelling damageability of structural and non-structural components of various type of buildings and their contents for various levels of flooding, and additional living expenses and business interruptions stemming from these damages. A component-based approach that considers the building structure, building use, fixtures and fittings, and services (i.e., mechanical, electrical, and plumbing) is used to estimate damage. Additionally, other features such as custom flood protection, first floor height and foundation types are implemented to reflect local construction and mitigation practices. Validation of the model was accomplished by comparing model results with published post event surveys by European research groups, focusing on the 2002 and the 2013 Central European Floods. The estimated damage ratios modeled compare well with published damage reports.
\end{abstract}

\section{Introduction}

Inland flooding is one of the most frequent natural hazards in Europe. Between May 30 and June 2, 2013, heavy rainfall over Central Europe caused floodwaters to rise to their highest levels, surpassing those observed during the Elbe flood in 2002 in some areas. The costliest natural catastrophe of 2013 incurred insured flood losses close to EUR 2.0 billion in Germany alone (Zurich, 2014), with further losses in Austria, Czech Republic, and Poland. This and other damaging floods during the past decades have demonstrated that understanding and managing flood risk in Europe has never been more critical.

Today, Catastrophe Models (CAT) just like the ones developed by AIR have become a key tool used by government agencies, catastrophe risk managers and insurance companies to optimally allocate resources and develop sound business strategies. AIR flood catastrophe models provide a probabilistic approach for determining the likelihood of various levels of losses from inland floods. The model consists of (1) an event generation module created from a continuous simulation of precipitation patterns and employs a hydrological model to quantify the excess runoff over the land and through river streams, (2) an intensity generation module that calculate water inundation depths and extents from a physicallybased hydraulic model, (3) an engineering module, in which damage to each building is estimated using damage functions, that is, functions that relate water depths to building damage, content damage and resulting restoration and repair time in calculating additional living expenses and business interruption losses and (4) a financial module where insurance policy term are applied (if any), and loss estimates are calculated (Figure 1).

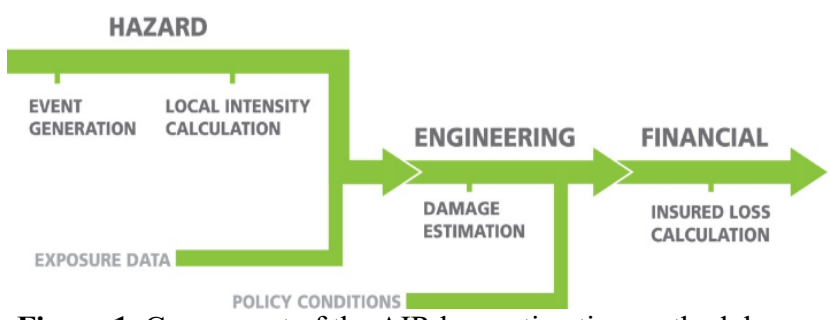

Figure 1. Component of the AIR loss estimation methodology

Various approaches to create flood damage functions have been published throughout the years (Messner et al. (2007)). Many studies focus on the analysis of statistical data from the aftermath of extreme flood events (Thieken et al (2008)); while others are developed from a synthetic approach (Dottori et al 2016), where estimates of repair cost of the building are calculated for various water depths. The underlying assumptions and limitations associated with the existing flood damage functions repositories indicated in Messner et al. (2007) is that a database of damage functions was not found for all the 5 countries considered in this study (Germany, Austria, Switzerland, 
Czech Republic and Poland). In addition, existing damage functions, found in the literature, lack to differentiate for the entire suite of occupancy, construction and height combinations of buildings that are typically required to perform probabilistic loss analysis in CAT models. Furthermore, existing curves do not explicitly consider the elevation of the first floor in buildings, that is a critical determinant of flood damage. Finally, information of presence of a basement, year built, location of service equipment in buildings, are some of the other aspects that are not explicitly captured in existing damage functions.

The subsequent sections of this paper focus on the development of building and contents flood damage functions for Central European Countries. A component level framework was used to estimate engineering damage functions to cover a wide range of primary building features (e.g. occupancy, number of stories and construction types) and secondary features of first floor height and presence of basements. Available research publications, damage surveys and loss data were used to validate the estimated damage functions.

\section{Component Level Framework for Generating Damage Functions}

The AIR model uses damage functions that relates the flood depth (intensity) to a mean damage ratio (MDR). The MDR represents the average repair-to-replacement ratio for an exposure when subjected to a certain flood depth. The uncertainty around the MDR is explicitly captured through probability distributions in the model. This paper focuses on the estimation of the MDR for various types of buildings and their contents.

To estimate the building flood damage functions the authors adapted the component level framework described by Ramanathan et al (2014) that was used to build storm surge damage functions for the United States. This approach is particularly well-suited to access water damage because it explicitly quantifies losses to the floodable components of the buildings that are impacted below the depth of flooding.

In the European damage function generation model, a building is divided into three main key components (Table 1 ), which collectively make up its total replacement cost.

\begin{tabular}{|c|c|}
\hline Component & Description \\
\hline Structure & $\begin{array}{c}\text { All load-carrying structural parts of } \\
\text { the building including the } \\
\text { foundation, roof frame, structural } \\
\text { envelope, and exterior walls. }\end{array}$ \\
\hline $\begin{array}{c}\text { Interiors and } \\
\text { Fixtures }\end{array}$ & $\begin{array}{c}\text { Interior walls (e.g., partition walls } \\
\text { and drywall), flooring and floor } \\
\text { coverings, and other interior } \\
\text { finishes. }\end{array}$ \\
\hline Services & $\begin{array}{c}\text { Heating, ventilation, and air } \\
\text { conditioning (HVAC), electrical, } \\
\text { and } \\
\text { plumbing systems }\end{array}$ \\
\hline
\end{tabular}

Table 1. Key building floodable components
To build the component damage functions, for Central Europe, the model uses results of studies conducted in the United Kingdom. The Multi Colored Manual (MCM) (Penning-Rowsell et al. 2005) provides estimates of overall building losses itemized by multiple building items for residential and commercial structures. The MCM residential cost data identifies major building fabric items to approximate losses by water depth bins. These loss estimates are derived from surveys and engineering opinion from experts in the field of construction, repair damage costs and insurance. After grouping the relevant MCM building fabric items into the three category of building components (based on the descriptions provided in Table 1), the losses obtained for different depth bins are divided by their respective replacement values to generate component level damage functions. Component level damage functions for commercial structures didn't required extra post- processing from the data. These are already developed from survey data and categorized by the key components indicated in Table 1 . The manual provides a range of minimum to maximum component level damage function estimates extracted from survey data. For this study, we focus on using the low susceptibility level class since it mainly represents buildings without the presence of a basement.

Figure 2 shows the component damage functions that were developed in this study (from MCM data manual) for a one-story masonry residential dwelling (e.g. detached single-family house). It can be observed that the most susceptible floodable components of the buildings are the fixtures (with interiors) and services, while the structure component is the least vulnerable.

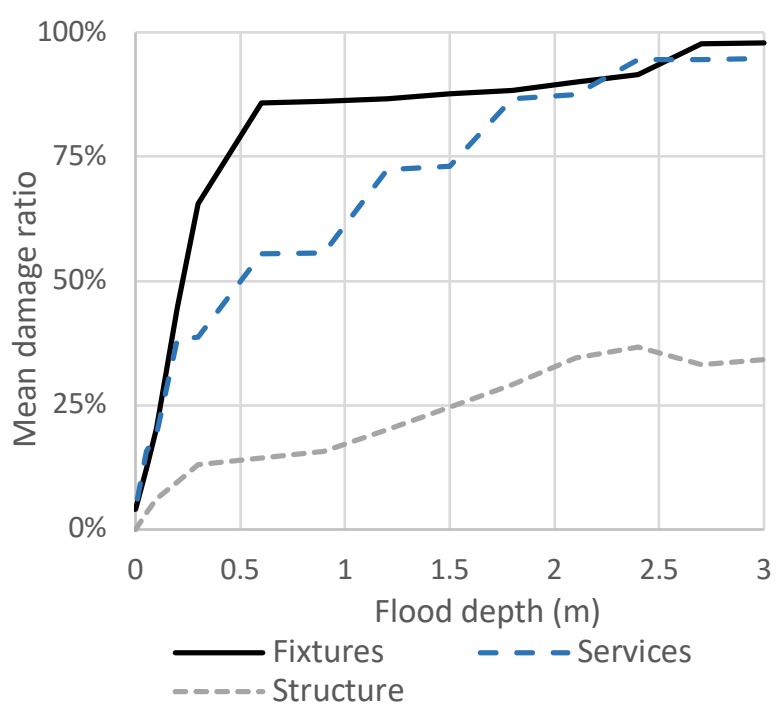

Figure 2. Component level damage functions for a one-story masonry single-family house.

The overall building damage function $\left(D F_{\text {building }}\right)$ is then obtained by applying equation (1), where a weighted average is calculated for each number of stories based on the proportion of replacement value attributed $\left(\alpha_{i}\right)$ to each component damage function $\left(D F_{C o m p, i}\right)$. The component replacement values $\left(\alpha_{i}\right)$ are extracted from multiple sources. We relied on the MCM manual data that mainly 
covered cost data for conventional residential and commercial buildings such as retails, restaurants, etc... For more complex engineered structures such as mid-rise and high-rise multi-story buildings the model uses data from RSMeans (2011).

$$
D F_{\text {building }}=\sum_{j=1}^{N} \sum_{i=1}^{3} \alpha_{i} \beta_{j} D F_{\text {Comp }, i}
$$

The component level damage function in Equation (1) are then aggregated vertically over the height of the building, $(N)$, based on a distribution factor $\left(\beta_{i}\right)$ for a component at a given floor level. The different distribution $\left(\beta_{i}\right)$ factors allow us to properly allocate the value across stories. For example, the electrical and mechanical fittings are generally located on the lower floors or basement, and therefore can exacerbate the extent of flood damage. Table 2 shows the relative vertical distribution of the six key components for multi-story residential buildings. Multi-story building distribution factors $\left(\beta_{i}\right)$ are assumed for each floor based on engineering judgement.

\begin{tabular}{|c|c|c|c|c|}
\hline $\begin{array}{c}\text { Foundation } \\
\text { type }\end{array}$ & $\begin{array}{c}\text { Story } \\
\text { Number }\end{array}$ & Structure & Services & Interiors \\
\hline Basement & 1 & $11.8 \%$ & $9.6 \%$ & $1.2 \%$ \\
\hline & 2 & $23.6 \%$ & $3.2 \%$ & 12.0 \\
\hline & 3 & $23.6 \%$ & $3.2 \%$ & $11.8 \%$ \\
\hline & Total & $59.0 \%$ & $16.0 \%$ & $25.0 \%$ \\
\hline
\end{tabular}

Table 2. Example of the product $\alpha \beta$ for a multi-story apartment reinforced concrete building

Many features contribute to a building's flood vulnerability and must be considered when determining how much damage water will inflict. As noted in the introduction of this paper is important for CAT models to have a robust engineering module that is flexible enough to represent numerous types of structures. The property location, its occupancy type, construction, height, and year built are the primary determinants of that structure's vulnerability to flood and its data that is usually gathered by CAT modelers users. But there are also several secondary risk characteristics that can have a significant impact on losses. For example, the height of the first floor and the foundation type that relates to the presence of a basement are also critical determinants of flood vulnerability (Wojtkiewicz, 2016).

\subsection{Damage Functions for Primary Features of Occupancy, Construction, Number of Stories and Year Built}

As stated in Ramanathan et al. (2014), it is essential in a CAT modelling framework to capture extensive yet realistic data that is representative of the study region building inventory. Damage surveys, satellite images and research publications (AIRWorldwide, 2013; Nemry et al. 2008; TABULA, 2012) have been used to understand the flood response of the Central European Countries built environment in terms on construction materials and building construction practices (including the adoption and enforcements of building codes).
Masonry and concrete constructions types dominates the building stock in Central Europe and flood protection measures typically enacted by the countries are in the form of early warning systems and construction of levees after major flood events. AIR CAT models the presence of major levees, dams and dikes in the event and intensity calculations module (Reiche, 2012). Since flood mitigation practices are not enforced in building codes, any major differences by year in building's response to flood forces were not expected.

The framework rather focusses on building damage functions for a finite number of building typologies based on the occupancy, construction material and number of stories combinations. Table 3 shows the most common construction types used in Europe. The effect of construction type is pronounced in the structure component damage function.

\begin{tabular}{|c|c|}
\hline Class & Description \\
\hline Wood Frame & $\begin{array}{l}\text { Mostly structures of } 1 \text { to } 3 \text { stories. } \\
\text { Stud walls constructed of } 2 \text { " x } 4 \text { " or 6" } \\
\text { wood members vertically set } 16 \text { or } 24 \\
\text { "apart. Walls are braced by plywood } \\
\text { or by wood or steel diagonals. }\end{array}$ \\
\hline $\begin{array}{l}\text { Masonry } \\
\text { Veneer }\end{array}$ & $\begin{array}{l}\text { Wood frame structures with one width } \\
\text { of non-loadbearing concrete, stone, or } \\
\text { clay brick attached to the stud wall. }\end{array}$ \\
\hline $\begin{array}{c}\text { Unreinforced } \\
\text { Masonry }\end{array}$ & $\begin{array}{l}\text { No steel reinforcing within a load- } \\
\text { bearing masonry wall. Floors, roofs, } \\
\text { and internal partitions in bearing wall. } \\
\text { Usually wood buildings. }\end{array}$ \\
\hline $\begin{array}{l}\text { Reinforced } \\
\text { Masonry }\end{array}$ & $\begin{array}{l}\text { Consists of load-bearing walls of } \\
\text { reinforced brick or concrete-block } \\
\text { masonry. Floor and roof joists } \\
\text { constructed with wood framing } \\
\text { common. }\end{array}$ \\
\hline $\begin{array}{l}\text { Reinforced } \\
\text { Concrete }\end{array}$ & $\begin{array}{c}\text { Consists of reinforced concrete } \\
\text { columns and beams }\end{array}$ \\
\hline Steel & Consists of steel columns and beams \\
\hline Light Metal & $\begin{array}{l}\text { Made of light-gauge steel frame and } \\
\text { usually clad with lightweight metal or } \\
\text { asbestos siding and roof, often } \\
\text { corrugated. Typically, these are } 1,2 \text {, } \\
\text { or 3-story structures. }\end{array}$ \\
\hline Unknowns & $\begin{array}{l}\text { Represents a weighted average of all } \\
\text { the above construction types. }\end{array}$ \\
\hline Caravans & $\begin{array}{l}\text { Manufactured homes that are built in a } \\
\text { factory and transported to their } \\
\text { permanent site. Different functions are } \\
\text { provided to account for different types } \\
\text { of anchorage. }\end{array}$ \\
\hline
\end{tabular}

Table 3. Common Construction Classes used in Europe

To model the different vulnerabilities by occupancy, type the derived component level damage functions capture the differences between the residential and nonresidential (e.g. commercial, industrial) lines of business. Because the breakdown of replacement values by component is different by number of stories and for the occupancies supported in the CAT model, building 
vulnerability is explicitly captured for the primary features of occupancy, construction and number of stories.

\subsection{Presence of a Basement and First Floor Height}

Given that, the damage functions are built per floor, the flood damage functions for buildings with a basement can easily accommodate damage estimates for underground structures. While individual floor level damage functions are aggregated based on flood depth from floor level, the final flood damage functions for the AIR Inland Flood CAT model are developed as a function of flood depth from the ground level. Figure 3 depicts an example how the damage function framework captures the basement floor damage for a one-story concrete retail commercial building. It is important to note in case of basement damage accumulates very quickly at low depths and the magnitude of estimated losses are driven by the product of $\alpha$ and $\beta$ distributions already explained in Equation (1). Similarly, Figure 3 also represents how the model accounts for variations in first floor height by protecting the no basement building damage function until the water depth exceeds 0.3 meters.

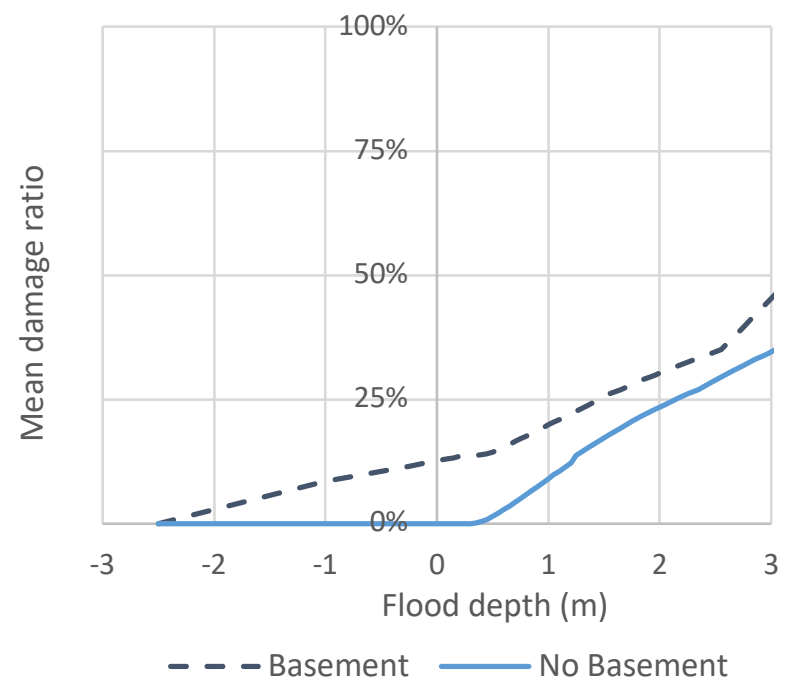

Figure 3. Damage functions for one-story concrete retail commercial building

\subsection{Content Damage Functions}

Comparable to the building, AIR built the contents damage functions based on a function that represents the losses of vulnerable contents for a given floor. The onestory content damage function is then aggregated vertically over the height of the building based on the fixture and interior component cost breakdowns used to calculate the building damage functions.

Component damage functions for contents are also derived from MCM manual results. Residential content damage functions primarily consider items that represent the furniture stock, while the commercial component damage functions reflect the combination of building stock and movable equipment.

\section{Building Regional Damage Functions for Unknown Primary and Secondary Characteristics}

So far, this study has described state-of-the art damage function generation framework to estimate flood damage for Central European Countries where information of occupancy, construction number of stories, presence of a basement and first floor height are collected in the exposure data.

Although the benefits of having detailed building attributes cannot be overstated, there are times that analyses performed using CAT models often lack primary and secondary building characteristics in the exposure data. In the absence of such detailed building characteristics data, it is important to assign a damage curve to a building that captures the local building practices at a regional level.

For modelling multiple combinations of unknown characteristics damage functions are built by using weighted averages of damage functions for buildings for which these characteristics are known. Different damage functions are used, depending on how many variables, and which ones, are unknown. Table 2 shows an example of the attributes considered for building unknown construction damage functions for Europe. To account for all combinations of primary characteristics, including unknown construction, occupancy and height the model uses CRESTA zones (CRESTA, 2021) level building inventory weight, derived from AIR's industry exposure database (Hayes et al. (2021)). The unknown damage functions also reflect a weighted average of secondary risk characteristics of foundation type and first floor height. Distributions obtained for the secondary building features were partly derived from satellite image surveys.

The figure below shows examples how the Industry Exposure significantly enhances modelling of these unknown combinations by considering local building attributes at the CRESTA level. As illustrated in Figure 4, the differences in building stock affect the damage functions. Oranienburg (CRESTA DEU_16) has a higher percentage of low-rise buildings than the Berlin CRESTA (DEU_13), which causes the unknown height damage function for Oranienburg to be closer to low rise building function than Berlin and thus more vulnerable to flooding (Figure 4).

\section{Validating AIR Damage Functions against Published Research}

Damage functions developed by aforementioned methodology and data were then evaluated against various data sources. Most of the damage information was collected from Germany, therefore the estimated Germany damage functions are used against observational data. It is important to mentioned that the damage function evaluation must be done with caution given that different model uncertainties are embedded in each source (Messner et al. (2007)). For example, damage functions may be built for various hazard and exposure model resolutions (macro, meso and micro scales). 


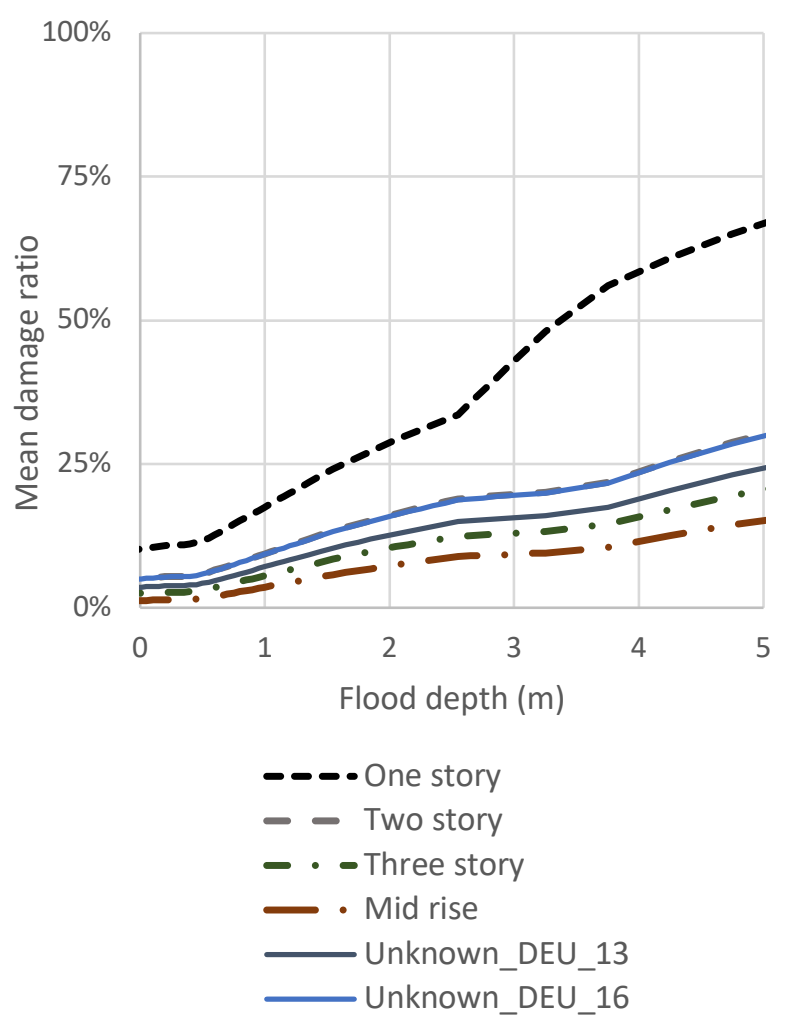

Figure 4. Unknown height masonry commercial damage functions for two CRESTA zones in Germany

Figure 5 shows the Germany model one-story singlefamily home building damage functions (with other primary and secondary characteristics as unknow) compared to multiple state-of-the-art flood models. The MURL (MURL, 2000), ICPR (ICPR, 2001), and HYDROTECH (HYDROTECH, 2001a; HYDROTECH, 2001b) models are all mesoscale stage-damage functions that worked to estimate losses at the regional level. The damage curve from EU Science Hub (2007) was derived from European survey data collected at the country level. It can be observed from the figure that AIR damage function falls within the bounds of these models.

Figure 6 shows the model Germany single-family home building damage function (with unknown primary and secondary characteristics) against the single-family home micro-scale FLEMOps (Thieken et al. (2008)) flood loss damage functions. The FLEMOps model was developed based on survey data from individual households in Germany that were affected by the flood in August 2002. The graphs show good consistency between the AIR model and the surveyed based model at different water depth bands. In general, AIR flood damage functions are lower than the observed data this is expected given that the model's damage functions provide estimates of the mean, or expected, damage ratios corresponding to the hazard at each site. These mean damage ratios reflect the average of damaged and undamaged properties as a result of hazard uncertainty, and flood resistance. In the FLEMOps data, all the properties are damaged. Hence, the estimated model damage function is generally lower than the observed at lower water depths. At high levels of hazard intensity, the proportion of the buildings that are undamaged are low.
The FLEMOps data sources have also been used to evaluate relative vulnerability for primary and secondary features. Figures 7 and 8 depicts the relative vulnerability (at different flood depth ranges) between apartment, multifamily homes and single-family homes damage functions observed by FLEMOPs against the model Germany damage functions for unknown foundation, construction and number of stories. As illustrated, both models display similar relativities between these occupancy types across different intensities.

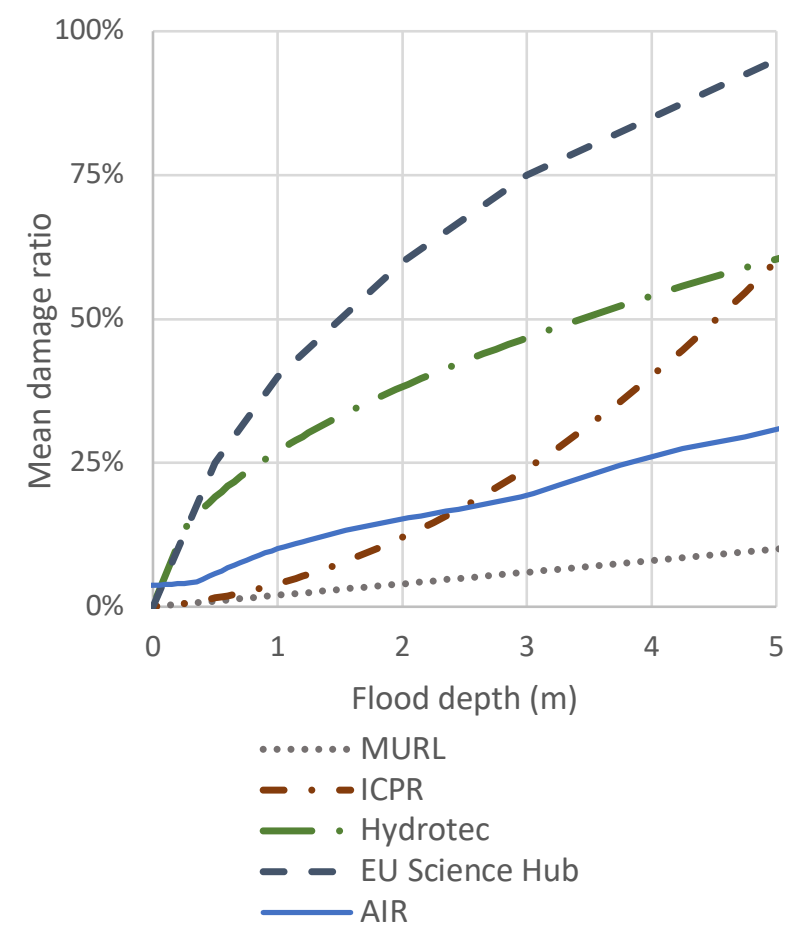

Figure 5. AIR Germany one-story single-family home damage function vs. various state-of-the-art models.

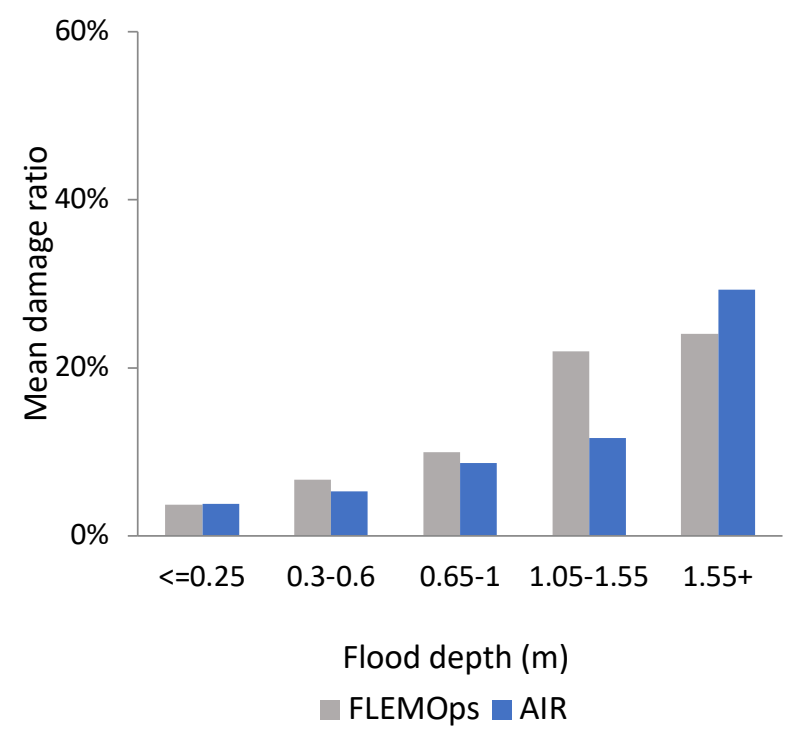

Figure 6. AIR Germany single-family home damage function vs. FLEMOps function one-family home

Additionally, relative vulnerabilities of secondary features have also been evaluated when data is available. 
Figure 9 and Figure 10 show the relative vulnerability of building and contents between residential buildings with and without a basement. A building without a basement serves as the base. In the charts, both the observed data and the model indicate that the building and contents for the structure with the basement are more vulnerable than for the structure without a basement.

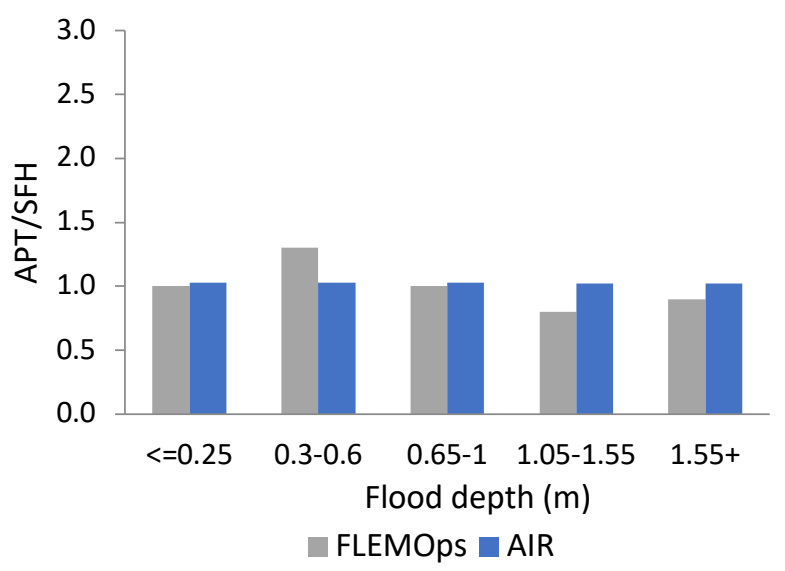

Figure 7. Relative vulnerability, apartment (APT) and singlefamily home (SFH), observed (FLEMOps) vs. AIR

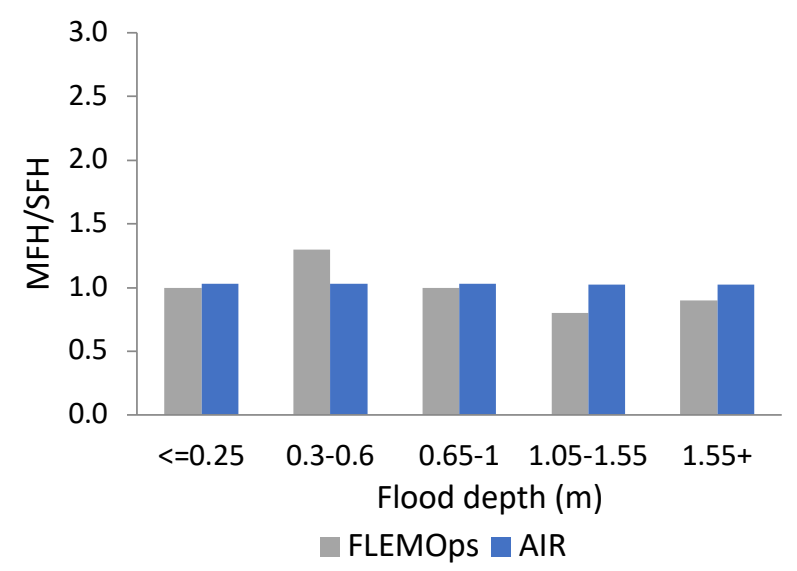

Figure 8. Relative vulnerability, multi-family home (MFH) and single-family home (SFH), observed (FLEMOps) vs. AIR

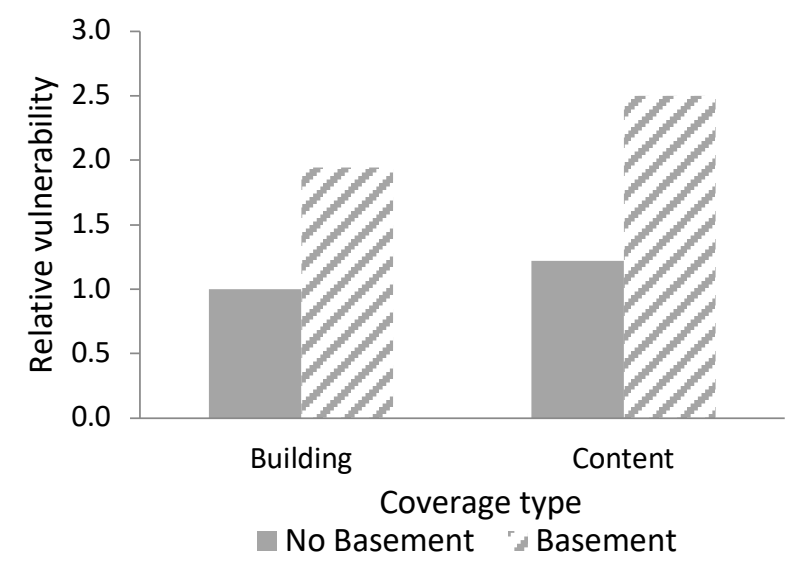

Figure 9. Relative vulnerability between foundation types, observed data from German survey of private households of Saxony and Saxony-Anhalt (Kriebich, et al., 2002)

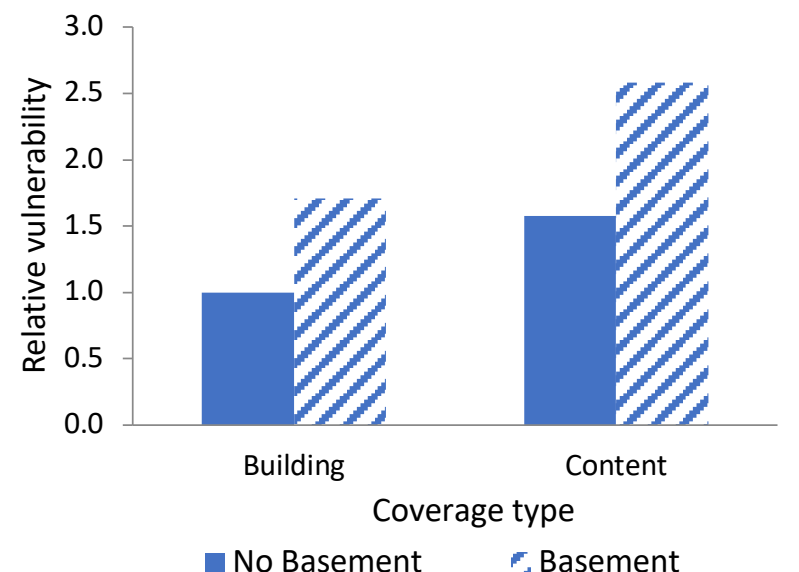

Figure 10. Relative vulnerability between foundation types, in the AIR model, single-family home, masonry

The figures depicted in this section concluded that the AIR model damage functions are not only comparable with other state-of-the-art flood models, but also validates well with survey-based empirical model in terms of both primary risk features (such as occupancy) and secondary risk features (such as foundation type).

\section{Conclusions}

The paper presents a component level framework used to generate damage functions in Central Europe. The adopted framework accounts for relevant floodable components of building structure and contents to estimate losses for AIR's CAT model engineering module. Damage functions explicitly incorporate various building features such as construction type, building height, foundation and first floor height. For CAT models, additional considerations are necessary to capture regional vulnerability among the countries when information pertinent to detailed building characteristics is missing. Regional building inventory information was used to properly assign the vulnerability in the absence of such information. Overall, the AIR inland flood damage functions for Central European countries compares well with observed data and other research publications.

\section{References}

1. AIRWorldwide (2013). Mapping the 2013 Floods in Central Europe. AIR Currents. Available at:

https://www.airworldwide.com/models/flood2/Mapping-the-2013Floods-in-Central-Europe/

2. CRESTA (2021), "CRESTA Zones \& Maps". CRESTA. https://www.cresta.org/zones-maps

3. Dottori, F., Figueiredo, R., Martina, M. L. V., Molinari, D., and Scorzini, A. R. (2016): INSYDE: a synthetic, probabilistic flood damage model based on explicit cost analysis. Nat. Hazards Earth Syst. Sci., 16, 2577-2591, https://doi.org/10.5194/nhess-162577-2016.

4. Hayes, C., Beston, C. (2021). Modeling Fundamentals: AIR Industry Exposure Databases. 
AIR Currents. Available at https://www.air-

worldwide.com/publications/air-

currents/2021/modeling-fundamentals-air-industry-

exposure-databases/

5. HYDROTEC (2001a): Hochwasser-Aktionsplan Lippe. Teil I: Berichte und Anlagen. Studie im Auftrag des StUA Lippstadt, Aachen.

6. HYDROTEC (2001b): Hochwasser-Aktionsplan Angerbach. Teil I: Berichte und Anlagen. Studie im Auftrag des StUA Düsseldorf, Aachen

7. ICPR (2001). Atlas on the risk of flooding and potential damage due to extreme floods of the Rhine. International Commission for the Protection of the Rhine (ICPR).

8. Messner, F., Penning-Rowsell, E., Green, C., Meyer, V.; Tunstall, S.; Van der Veen, A. (2007). Evaluating flood damages: guidance and recommendations on principles and methods.EU Floodsite project $\mathrm{N}$. GOCE-CT-2004-505420.

9. MURL, Ministerium für Umwelt, Raumordnung und Landwirtschaft des Landes Nordrhein-Westfalen (2000). Potentielle Hochwasserschäden am Rhein in NRW, Düsseldorf.MURL Report.

10. Nemry, Françoise and A. Uihlein (2008).

Environmental Improvement Potentials of

Residential Buildings (IMPRO-Building). JRC, European Commission

11. Penning-Rowsell, E., Johnson, C., Tunstall, S.,Tapsell, S., Morris, J., Chatterton, J., and

12. Green, C. (2005). The Benefits of Flood and Coastal Risk Management: A Handbook of Assessment Techniques. London, United Kingdom: Middlesex University Press. ISBN 1-904750-51-6

13. Ramanathan, K., Kafali, C. (2014). Component Level Framework for Developing Storm Surge Damage Functions for Application in Catastrophe Models. Structures Congress, https://doi.org/10.1061/9780784413357.125

14. Reiche, A (2012). Setting the New Standard in Modeling Flood in Germany and Across Europe. AIR Currents. Available at: https://www.airworldwide.com/publications/aircurrents/2012/Setting-the-New-Standard-inModeling-Flood-in-Germany-and-Across-Europe/

15. RSMeans (2011). "RSMeans Square Foot Costs." RSMeans, 32nd Ed., Massachusetts.

16. TABULA (2012). https://episcope.eu/ieeproject/tabula/

17. Thieken, A. H., Olschewski, A., Kreibich, H., Kobsch, S. \& Merz, B. (2008). Development and evaluation of FLEMOps - a new flood loss estimation model for the private sector. WIT Trans. Ecol. Environ. 118, 315-324 (2008).

18. US Army Corps of Engineers (USACE) (2006). "Depth-Damage Relationships for Structures, Contents, and Vehicles and Content-to-Structure Value Ratios (CSVR) in Support of the Donaldsonville to the Gulf, Louisiana, Feasibility Study." USACE, New Orleans District, Louisiana.

19. Wojtkiewicz, R (2016). Worth the Effort: Collecting Secondary Risk Characteristics for Improved Flood Risk Management. AIR Currents. Available at: https://www.air-worldwide.com/publications/aircurrents/2016/Worth-the-Effort--CollectingSecondary-Risk-Characteristics-for-Improved-FloodRisk-Management/

20. Zurich (2014). Risk Nexus, Central European floods 2013: a retrospective. Available at: https://www.zurich.com/en/knowledge/topics/floodresilience/risk-nexus-central-european-floods-2013a-retrospective 